\title{
Employment, Social Mobility and Neighbourhood Effects: The Case of Sweden
}

\author{
SAKO MUSTERD and ROGER ANDERSSON
}

\begin{abstract}
In science and in society at large, there is a big debate going on about the existence and potential impact of 'neighbourhood effects'. The dominant question is: does the social composition of the neighbourhood have specific positive or negative effects on the career prospects of those who are living there? We seek to contribute to this debate by investigating the relationship between individual social mobility and the social composition of the residential environment. For that purpose we analysed new longitudinal Swedish data, which is available at the individual level. We particularly focused our attention on the employment careers of individuals in relation to the levels of employment or unemployment in their individual environments. Environment effects on social mobility were isolated, controlling for relevant variables that were available at the individual level. We were also able to control for changes in the environments over time. Individual longitudinal data could be used over the period 1991-9. The analyses revealed that their environment appears to have a moderate yet clear impact on the employment prospects of unemployed individuals. The academic relevance of the article is in its contribution to the theoretical underpinnings of the human-environment relationship; the societal relevance is to the area-based policies and the housing policies aimed at social mixing, which are currently being developed in many places in the Western world.
\end{abstract}

\section{Introduction}

It is widely believed that the neighbourhood in which a person lives and grows up makes a difference to the opportunities for social mobility that are available to that person. Children, adolescents and adults supposedly receive many inputs in the course of their lives from the neighbourhood they live in; these inputs will differ for different people, but they will not be irrelevant, it is argued. They can be both positive and negative. Individuals may learn certain skills and behaviours from their neighbours, and these model-learning experiences and socialization processes can help them to get along in their own lives. However, some environments may also block upward mobility. So, neighbourhoods can offer certain positive, but also certain negative resources. A neighbourhood may have a good reputation, but it may equally well have a bad one, and as a result it will be labelled as attractive or unattractive. In addition, places can have a good or a bad record in terms of the social and physical qualities and the services and institutions available; this may or may not help people to get on in life. Neighbourhoods are also characterized by their location, which is their position relative to other important places. Location relative to economic centres where people can find a job may have an impact, but so also may location relative to places where health

A first version of this article was presented at the ISA-RC21 conference Challenging Urban Identities, University of Milano-Bicocca, 25-7 September 2003. 
services are based, where recreation facilities can be found, and so on. In short, neighbourhood reputation, social composition and socialization processes in the neighbourhood, as well as local social networks and neighbourhood services may impact upon people's lives, independently of individual and household attributes that may also affect their opportunities; the results will be visible as neighbourhood effects.

In this article we aim to contribute to the knowledge of neighbourhood effects on individual careers by trying to answer the following question: To what extent does the social composition of a neighbourhood have specific positive or negative effects upon the career prospects of those who are living in it?

Before we present a short review of the relevant literature, some attention will first be paid to the relation between the neighbourhood effect debate and today's housing mix policies. That societal debate appears to be a strong 'trigger' for the academic efforts aimed at understanding neighbourhood effects as well. Our literature review will, necessarily, be short and rather selective. The neighbourhood effect literature has become very extensive and deals with effects on various aspects of life, such as social and labour career opportunities, crime, deviant behaviour, health, the risk of teenage pregnancy, educational attainments and the development of social capital through social networks. We will present some theoretical justifications for expecting neighbourhood effects, but the focus of the article is primarily empirical and the theories are of a type that makes them difficult to test in one particular empirical study.

In the empirical sections of this article, which cover the data used and the empirical outcomes respectively, we will show that we are able to reply to serious critiques that have been brought forward with regard to the majority of neighbourhood effect research (see, for example, Atkinson and Kintrea, 2001; Galster, 2002). That is, we are able to show the results of a longitudinal analysis, using large-scale individual data and focusing on all types of environments, i.e. not only the poorest; we are also able to include individual and family household information and, by doing so, can introduce more relevant control variables. The data also allow us to test for the form of the relationship between the social composition of the neighbourhood (percentage poor) and the aggregate social problems. Often a specific non-linear relation is assumed. That assumption underpins the so-called mixed housing policies, which can be found all over Europe now. In this research we are able to test this assumption. The article concludes with a short evaluation.

\section{Neighbourhood effects and housing mix policies}

Today, politicians and other actors who are concerned with urban social issues tend to prefer area-based or area-related strategies to tackle these problems. Preference for these strategies can be found in governmental circles, in housing associations, among academics, and in other arenas where these topics are dealt with. For some countries, like Sweden, this also means a shift from general and universal welfare approaches to more selective ones. A special form of area-based intervention is the so-called mixed housing strategy to achieve a social mix of the population at the neighbourhood level (Musterd and De Winter, 1998; Musterd et al., 1999; Atkinson and Kintrea, 2001; Ostendorf et al., 2001; Uitermark, 2003; Musterd and Andersson, 2005). Housing and social mix, usually through tenure diversification, is often regarded as having very positive effects upon people's lives. Mix enhances housing choice within the neighbourhood and thus avoids the need to move when the household's choice level increases. That implies a reduction of social separation due to lack of supply. Therefore, mix reduces the social exclusion of the poor. In many cities, for example in the UK, Sweden, the Netherlands and elsewhere, this belief - that diversification of the population helps to 'enrich' social networks and to create new interaction opportunities for, particularly, poor households — is strongly developed. Since it is difficult to realize the social mix objectives directly, it often occurs through tenure diversification (see, for example, Jacquier, 2001; Kearns, 2002). In the report on 'The State of English Cities' 
(Robson et al., 2000), for example, it was argued that tenure mixing and social mixing are to be regarded as appropriate policy strategies to overcome the risk of neighbourhood effects.

In the North American literature similar housing policy ideas are articulated, albeit in a slightly different way. There, aims have been formulated to allow people to "move to opportunity', that is, to places that are supposed to offer better social opportunities. This also implies the supply of mixed housing environments in which both poorer and more affluent households can live 'together' (Galster and Killen, 1995; Rosenbaum et al., 2002).

\section{Literature review: why neighbourhoods have effects}

In fact, the housing mix and social mix strategies must be regarded as operational policy responses to theoretical ideas regarding neighbourhood effects that have been discussed in the literature for some time now. The idea has become widely shared that living in an area in which a high proportion of the population is in a disadvantaged situation will have negative effects on the residents. This can be illustrated by 'classic' studies on the cultures of poverty (Lewis, 1966), or by other 'classics' describing the grim results of social spatial processes in big metropolises, often in association with far-reaching economic restructuring processes (Wilson, 1987; Massey and Denton, 1993), as well as by more focused evaluations and reviews of neighbourhood-effect related policies and studies (special issues of Housing Policy Debate, 1995 and of Housing Studies, 2002 and 2003, but also extensive reviews by Ellen and Turner, 1997; Leventhal and BrooksGunn, 2000; Sampson et al., 2002). As was said before, various theories support these ideas.

The first theoretical field stresses the stigmatization effect of relatively large concentrations of deprived people, with subsequent negative impacts upon employment opportunities, etc. Negative images or reputations of neighbourhoods are especially harmful if important actors base their decisions on them. Redlining practices, for example, are often based on such images. Redlining implies that certain areas are regarded as 'risky to invest in'. Those who live in such areas may be confronted with other, stricter rules and reduced opportunities to get the services they need, such as affordable mortgages. These areas may then develop a negative stigma; it is almost as if they have been officially declared to be 'bad' environments, peopled with nasty residents. Such stigmas may have serious negative effects, especially if employers refrain from hiring people who live in the stigmatized areas. White (1998) reports such practices in the city of Paris, also referring to work by Wacquant ('territorial stigmatization') and Vieillard-Baron ('local stigmatization'). In other studies too, the link with stigmatization is formulated (e.g. Molina, 1997; Friedrichs, 1998; Atkinson and Kintrea, 2001; Farwick, 2002).

A second theoretical strand refers to the socialization processes and the quality of social networks in these neighbourhoods. A spatial concentration of unemployed people can provide 'unwanted' social ties and role models for those who still have to enter the labour market; that may imply that the basic skills needed to move ahead in society are not learned. Also the size and quality of social networks might impact upon the opportunities in neighbourhoods.

Sociologists like Wilson (1987) are among the many who say that the spatial separation of those who have and those who do not have prospects has resulted in a reduction of the opportunities open to the weaker part. In his view they are seriously hampered by the fact they do not get in touch anymore with those who provide 'good' role models and the right contacts. They are cut off from the resources and information that are required to get out of their miserable situation, and they are thereby cut off from the opportunity to enhance their social networks. Leventhal and Brooks-Gunn (2000) have provided an overview of the literature, particularly in this sphere, and illustrate the 
dominance of the socialization idea. A crucial assumption is that when poor people are gathered in large homogeneous concentrations, this will have a negative impact on their opportunities to integrate in urban society. This holds for large sections of immigrants, but also for other households with few prospects of getting ahead. Children and adolescents who are living in these environments run the risk of socializing with 'bad examples' as role models. These bad examples come from their peer group, which gains importance when children get older. If a majority of the neighbourhood population is unemployed, dealing drugs, frequently in prison, etc., then this situation may come in the end to be regarded as 'normal'. This could be the start of a culture of poverty, of the kind that Oscar Lewis (1966) had in mind some 40 years ago. In Sweden, R. Andersson (2001) explicitly refers to the extent, type and quality of the social network as potentially contributing to a neighbourhood effect. The development of networks along certain lines (age, gender, class, ethnicity) may stimulate or reduce the opportunities to discover new ways of life and may or may not prevent people from becoming trapped in a weak social position, he argues. These networks may be particularly important for adults, since they may need them to get the proper information about vacant positions and other opportunities. Some suggest that living in a dense neighbourhood social network is beneficial for residents, because people living in a more socially cohesive community are more apt to look out for their neighbours, to help them to overcome hard times and to share community news and information about relevant resources and jobs (Ellen and Turner, 1997).

A third type of neighbourhood resource, often mentioned in the literature, is access to and quality of local services, such as good-quality schools, available child care facilities, preschool services and after-school programmes, the quality of the staff providing these services, the quality of the materials used in schools, the level of attention, supervision and stimulation given to children, and also access to medical care. Individuals who lack these services in their vicinity may experience negative impacts upon social opportunities. Related to this is the spatial mismatch hypothesis arguing that job opportunities are not evenly distributed across urban space and that unemployed people may be spatially disconnected from relevant job opportunities. We think that this is probably a more relevant hypothesis in US than in Western European cities, the reason being the lack of good collective urban transportation systems in many US cities and a more substantial shift of job opportunities to the suburbs (Kain, 1968; 2004). However, this does not mean that spatial mismatch is of no significance at all in European cities.

A fourth dimension is the level of exposure to crime and violence. A high level of crime in the neighbourhood may again have negative effects in the sphere of socialization; but crime may also result in people becoming isolated, since many will continue to consider crime as deviant behaviour that poses a threat to them, which may result in a reluctance to leave the home.

However, irrespective of these plausible theories of neighbourhood effects, there appears to be only thin, if any, evidence for their existence. Even in the American context, where social and spatial inequality is much more evident and therefore impacts might be expected earlier, there is only mixed evidence of effects (Ellen and Turner, 1997). There are some authors who report empirically measured effects, for example in the framework of the Moving to Opportunity programmes (see Rosenbaum et al., 2002). But there are others who point to the selectivity and self-selection mechanisms, which may have distorted the results; they tend to examine these examples critically (Galster and Zobel, 1998; Galster, 2002).

There is even more reason to refrain from quick conclusions about neighbourhood effects in the European context. As Galster (2002: 8) says in the introduction of a special issue of Housing Studies on 'Opportunity, deprivation and the housing nexus: trans-Atlantic perspectives':

Fundamental is the difference in political economy, with Western Europe espousing a much more comprehensive social safety net, including income and housing support guarantees. As 
a consequence, Western Europe evinces far lower levels of racial-ethnic segregation, poverty rates, geographic concentration of poverty and criminality than in the US. Not surprisingly, given the comparatively modest variation in geographic and socio-economic context, debate continues among Western European scholars about the significance of neighbourhood as an independent effect on life chances.

European authors such as Friedrichs (1998), R. Andersson (2001), Atkinson and Kintrea (2001), Ostendorf et al. (2001), Whitehead (2002), E. Andersson (2004) and Musterd (2002) can be called upon to illustrate the European position. Most of them do not deny the existence of neighbourhood effects, but many clarify that these effects are relatively minor or not fully understood.

It is easy to imagine that neighbourhood-targeted special programmes may be required in situations in which a substantial proportion of the population is in trouble - and thus the role models for youngsters are drawn from those who are in trouble. In these environments we may even encounter situations of 'hypersegregation' and the reproduction of the ghetto as Massey and Denton (1993) and Wacquant (1993) argue. Here, the local social atmospheres, opportunities and networks may indeed be such that extra assistance is required to escape from these situations. However, it is hard to imagine that neighbourhood-targeted programmes make a lot of sense in environments where the vast majority already belongs to the category of promising role models or where people will be able to find these role models nearby.

Yet, we should not try to reach these conclusions too fast. The studies that have been carried out so far could be criticized for various reasons. There appears to be a great need for two further types of study, of which there have been few examples up to now. First, in-depth qualitative studies, which try to shed some light inside the black box of neighbourhood effect processes. Crucial questions in this type of research are: how actually does the socialization process evolve at the neighbourhood level? What is the impact of local peer groups on adolescent's behaviour, values and norms? Are social networks of poor (unemployed) people still predominantly local and what is their role in escaping from poverty? A good example of this kind of study is the work by BloklandPotters (2003) on social relations in a poverty-stricken neighbourhood in the city of Rotterdam, the Netherlands.

The second type of research, the type we aim to contribute to, is large-scale longitudinal research, which is required to test the neighbourhood effect hypotheses without in-depth analysis of what is in the black box of neighbourhood effect mechanisms. As far as we know, few such large-scale European studies have been carried out. This certainly holds true for studies that focus on the neighbourhood as a potential factor in understanding people's opportunities for social mobility. These are based on longitudinal datasets in which the construction of small neighbourhoods and their population composition was possible and in which there were sufficient cases to include several individual and context variables simultaneously. Two of these studies were conducted by ourselves (Andersson, 2001; Musterd et al., 2003) and were based on longitudinal data available in Sweden and the Netherlands. However, both studies should be regarded as first steps aimed at understanding the role of neighbourhood composition in the social mobility process of individuals, controlling for a set of relevant variables. Andersson (2001: 181) concluded in his research, which was focused on the Stockholm Metropolitan Region and based on analysis at the individual level of all 1 million inhabitants between 16 and 64 years of age, that there was 'an abundance of information on social indicators ... suggesting that the quality of life may vary substantially across urban space, even in a Scandinavian welfare state. However, it has not been shown whether such variations are caused by compositional differences alone or by additional contextual effects'. In his study he did find some indications pointing at effects, though. 'We are facing empirical regularity that calls for further research', he said (ibid.: 182). He makes a plea for extending the time period under consideration, and bringing in data on family background. 
Eva Andersson $(2001 ; 2004)$ used Swedish data for a longitudinal study of people living in three Swedish municipalities (population 90,000 to 130,000). The survey cohort consisted of individuals born in 1970, who lived for at least five years in the same area during their adolescence. The most important finding was that the socio-demographic and physical context of the residential area of adolescence affects the subsequent socio-economic career. This quantitative multi-level analysis showed that the individual's socio-demographic context during 1985-89 was significantly associated with the educational standard that he/she had reached by 1995. Musterd et al. (2003: 887) found in their research on 1.7 million Dutch households that, in the Dutch context, only small neighbourhood effects can be shown if one focuses on the unemployed: 'The conclusion can be drawn that the chance of escape [from unemployment] is dependent on the environment, but only to a minor extent'. In their research project, however, they could only indirectly incorporate essential variables such as the level of education.

Besides these large-scale studies in which individuals or individual households were followed over a period of time, there are also other interesting longitudinal and crosssectional studies that have been carried out. These were based on smaller samples. Even though these studies struggle with methodological problems, such as their smaller number of cases or with lack of longitudinal data, their findings do not seem to differ fundamentally from the larger-scale studies. Their conclusion too is that some effects may exist, but additional large-scale longitudinal research is required (e.g. Atkinson and Kintrea, 2001; Buck, 2001; Farwick et al., 2002).

Summing up, the Swedish and Dutch teams could apply the required longitudinal datasets, yet in both studies many shortcomings were mentioned. The time-period under consideration in both studies was rather short (five years only); some variables, like education, could not always be incorporated in an appropriate way; family household information was lacking; information on the changes individuals were undergoing during the research period (such as their level of educational attainment) was not part of these research efforts; and also other relevant dynamic variables, such as relocations during the research period, were not investigated in great depth.

Recently, however, it has been possible to compile a better and more extensive dataset. This offered us the opportunity to build on the research we did before and to respond to many critiques of current neighbourhood effect research. The data and methods we used to contribute to the debate are briefly discussed in the next section, which will be followed by a presentation of the empirical findings.

\section{Data, methods and variables used}

The database we used was provided by Statistics Sweden and derived from a whole set of registers, which were combined on the basis of the personal identification number each Swedish inhabitant receives at birth or at immigration. Selective longitudinal information over the period 1991-9 was made available in the database, for all Swedes individually. Data provision had to be approved by Statistics Sweden's Data Security Council and data storage and use are, due to the individual-level information, regulated in a contract. Of course, the researchers did not receive personal identification information. The data includes demographic information (such as sex, age, family size, number of children, country of birth, origin of parents), socio-economic data (on employment, income, education, benefits, etc.), some housing information (tenure and type) and detailed location information, that is, the coordinates of each grid of $100 \times 100$ metres a person lives in. The detailed geographic information enabled us to construct environments that were specific for each individual. On the basis of experiments and knowledge of the size of local environments that people regard as 'their' neighbourhoods, we decided to construct environments of $500 \times 500$ metres (i.e. 25 grids, extending 250 metres in each direction around each individual). For each individual such an environment was calculated in exactly the same way. So, when we 
talk about the social environment of an individual, we refer to the percentage of unemployed (for example) in the 25-grid space surrounding an individual, in which the individual is always in the central grid. The individuals were, of course, excluded from the calculation of the environments in order to avoid double counting.

Ideally, neighbourhood effect studies should incorporate multiple-level variables. We were able to include individual-level attributes (such as age, sex, country of birth of the individual or parents, level of education) some household attributes (family position, urban or non-urban orientation), crucial neighbourhood characteristics (the percentage of unemployed), and information on whether the individuals lived in one of the big metropolises (Stockholm, Göteborg and Malmö) or not. In this project we are not in a position to include exogenous neighbourhood characteristics, such as the perceptions from outside; neither did we include more detailed information on the economic structure of the metropolitan area. Although these dimensions may play an important role, incorporation of these dimensions was beyond the scope of this article.

We could, however, include several dynamic variables, such as the change in educational level, change in metropolitan status, change of place and change in family position. As far as the neighbourhood effect is concerned, we also regard it as crucial to look at the changes in the environment during the period under consideration. The environment may have changed relative to the starting position; that change may explain the (lack of) social mobility; the (lack of) social mobility then could not be completely understood by just looking at the character of the environment at the start of the period under consideration.

The data cover the period 1991-9 and we used the entire Swedish population aged 16-65 and followed them for eight years. More than 5.5 million individuals were included in the analyses. In terms of macro-economic conditions, the first part of the 1990s was characterized by an economic and employment crisis with rapidly expanding unemployment in 1992 and 1993, while the latter part, especially 1998 and 1999, was a recovery period. This is the primary reason for our choice of study period. The environment variable was calculated for 1991, 1995 and 1999, and in each of these years the percentage of unemployed relative to the 16-65-year-old population in each of the three years was calculated.

As far as the dependent variable is concerned, we are aware of the fact that social mobility can be measured in many ways, including intergenerational social mobility. Even when the focus is on one generation, different indicators may be used, such as the transfer from an unemployed status to an employed status or vice versa, or the change from an unstable employment position to a stable position; the move from a poor income to a higher income or the other way around; improvement in educational attainment level; change in social capital through stronger or weaker social networks; or change in social participation. We decided, for the moment, to focus on the change from unemployment into employment; that is, to focus on all Swedes (142,449 individuals) between 16 and 65 years of age (in 1991) who were unemployed in 1991; in another article we will also pay attention to the perhaps equally interesting change from a stronger position into a weaker position and the relation between that change and the environment. Change in educational attainment level will be used as an independent variable. Unemployment is defined on the basis of those who were really unemployed, i.e. people registered as unemployed the first week in November who had also received unemployment benefits during the same year. Others not working, such as students and people on old age pensions, were not defined as unemployed.

\section{On individual and neighbourhood effects}

Those who were unemployed at the start of the research period (1991) could be classified in four categories depending on their employment status in 1995 and 1999. Table 1 and Figure 1 show that almost a quarter of those who were unemployed in 1991 
were also unemployed in 1995 and 1999. Another 22\% found employment in the period between 1995 and 1999, whereas just over 8\% appeared to be employed in 1995 and unemployed again in 1999. Forty-six per cent seem to have been able to escape from unemployment. What is important for the purpose of this study, however, is the relation between the percentage of unemployed in the environment (first column in Table 1 and horizontal axis in Figure 1) and the percentage of those who were unemployed in 1991 in each of the categories distinguished. This relation can better be shown in a graph (Figure 1).

The graph clearly shows that there is no relation between the type of neighbourhood (weak or strong) and the percentage of individuals who entered the labour market and left it again (101), or only got a job after a longer period of unemployment (110). People who experience one of these two types of labour market careers seem to be rather vulnerable, but this does not seem to be related to the environment they live in.

The other two career types, however, show a firm neighbourhood effect. Except for the 'zero-per cent' category, it is clear that the probability of becoming employed (100) decreases if one lives in a weaker environment, whereas the probability of staying unemployed (111) increases. The probability that a person unemployed in 1991 would succeed in becoming employed in 1995 and 1999 is 56\% if that person lives in an environment with only $0-2 \%$ unemployed people; if he or she lives in an environment with $14-16 \%$ unemployment, the probability does not exceed 35\%! The reverse is true for those who stay unemployed. The risk that a person unemployed in 1991 would still be unemployed in 1995 and 1999 is only $16 \%$ if that person lives in an environment with only 0-2\% unemployed people, whereas that percentage would double to $32 \%$ if he or she lives in an environment with 14-16\% unemployed. The two patterns (100)

Table 1 Percentage of 16-65 years old who were unemployed in 1991 (1) and were still unemployed in 1995 (1) or not (0) and were unemployed in 1999 (1) or not (0), per environment type

Environment Type*

1991, 1995 and 1999

No.

\begin{tabular}{lrrrrr}
\hline 0 & 100 & 101 & 110 & 111 & \\
\hline $0-2$ & 50.6 & 8.8 & 20.4 & 20.2 & 15,446 \\
\hline $2-4$ & 56.3 & 7.2 & 20.5 & 16.0 & 12,911 \\
\hline $4-6$ & 51.0 & 8.0 & 21.7 & 19.4 & 30,105 \\
\hline $6-8$ & 46.7 & 8.1 & 22.7 & 22.5 & 30,753 \\
\hline $8-10$ & 42.1 & 8.7 & 22.8 & 26.4 & 22,765 \\
\hline $10-12$ & 39.0 & 8.9 & 22.6 & 29.5 & 14,237 \\
\hline $12-14$ & 37.2 & 9.3 & 23.4 & 30.1 & 7,158 \\
\hline $14-16$ & 36.2 & 9.0 & 24.0 & 30.8 & 3,870 \\
\hline $16-20$ & 35.0 & 8.9 & 24.0 & 32.0 & 2,407 \\
\hline $20-30$ & 40.6 & 8.8 & 22.9 & 27.7 & 1,565 \\
\hline $30-40$ & 39.6 & 10.1 & 22.4 & 27.9 & 771 \\
\hline $40-50$ & 38.8 & 11.2 & 21.9 & 28.1 & 260 \\
\hline $50-75$ & 46.6 & 7.4 & 18.0 & 28.0 & 189 \\
\hline Total & 25.0 & 8.3 & 33.3 & 33.3 & 12 \\
\hline & 46.3 & 8.4 & 22.1 & 23.2 & \\
\hline Per & 65,962 & 11,923 & 31,520 & 33,044 & 142,449 \\
\hline
\end{tabular}

*Percentage unemployed in the environment in 1991 


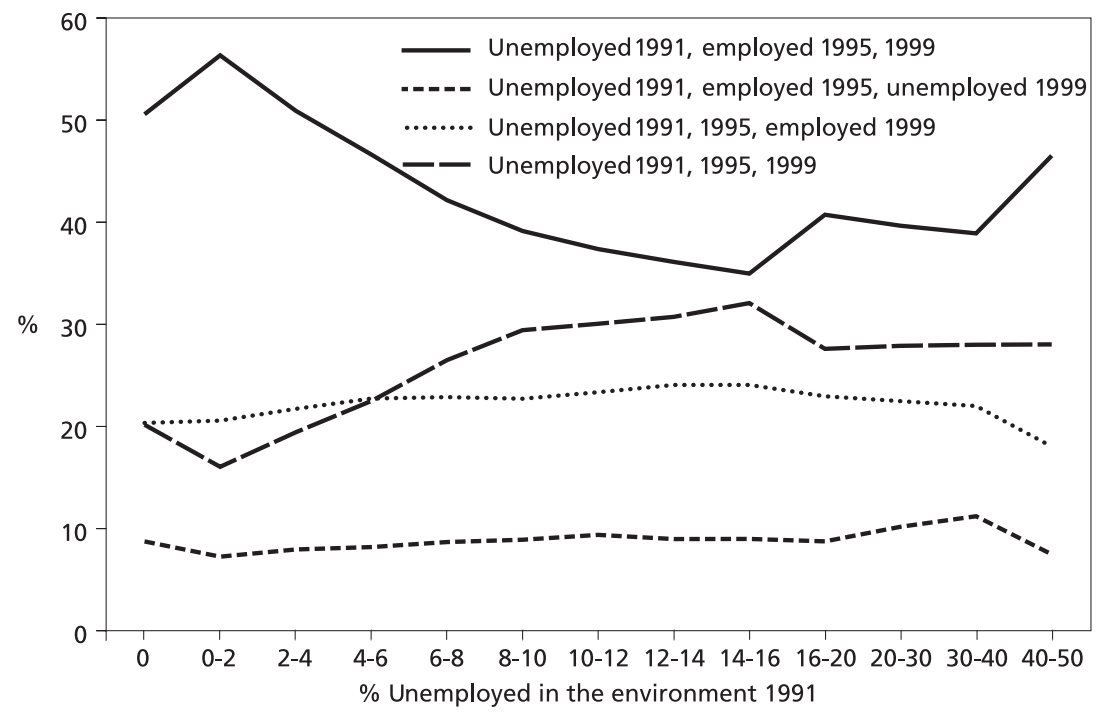

Figure 1 Four types of labour market careers of Swedes, 16-65 years old, who were unemployed in 1991, per environment type.

and (111) appear to mirror each other, which implies that we can focus on one of them to continue the analysis.

There are two clear breaks in the graphs. One is at the lowest end of the lines. This may be surprising but can be explained as follows. If a person is the only one who is unemployed in an environment, the environment has been labelled as ' $0 \%$ unemployed in the environment'. So, there is only one person unemployed, which is the person in question. This may, especially in less densely populated environments, result in a rather strong negative stigma on the individual, which might have some negative effects on the person's opportunities. The other break is at the $16 \%$ unemployed level. What happens after that break can only partly be explained by lower absolute figures. A hypothetical explanation may be that the welfare state is especially effective in addressing unemployment in 'problem areas', while it tends to be less effective in countering neighbourhood effects in somewhat less problematic environments. This hypothesis, however, requires further analysis, which is beyond the scope of this article.

We decided to continue with a focus on those who remained unemployed throughout the research period and not to focus the attention too much on the outer ends of the graphs.

As has been clarified in the theoretical discussion, employment opportunities may be triggered by the environment a person is living in, but may also be affected by other factors. In Western societies it is, for example, much easier for younger than for older unemployed to re-enter the labour market. The same holds for more highly educated people compared to people who are less well educated. Unequal spatial distributions of individuals according to age and education may, therefore, have considerable impact on the research outcomes and may even result in the disappearance of the neighbourhood effect. That is a reason to control for these variables. Figure 2 shows us that there is, indeed, a clear age effect as regards the probability of getting a job after unemployment; the older the person is the more difficult it is to get a job again; however, the neighbourhood effect is still there, in fact for all age categories.

With regard to education we decided not to look at the static educational level in a certain year, but at the dynamic variable 'change in the level of education'. We split the period in two. As stated, the 1991-5 period reflects a bust period in the economy, in 


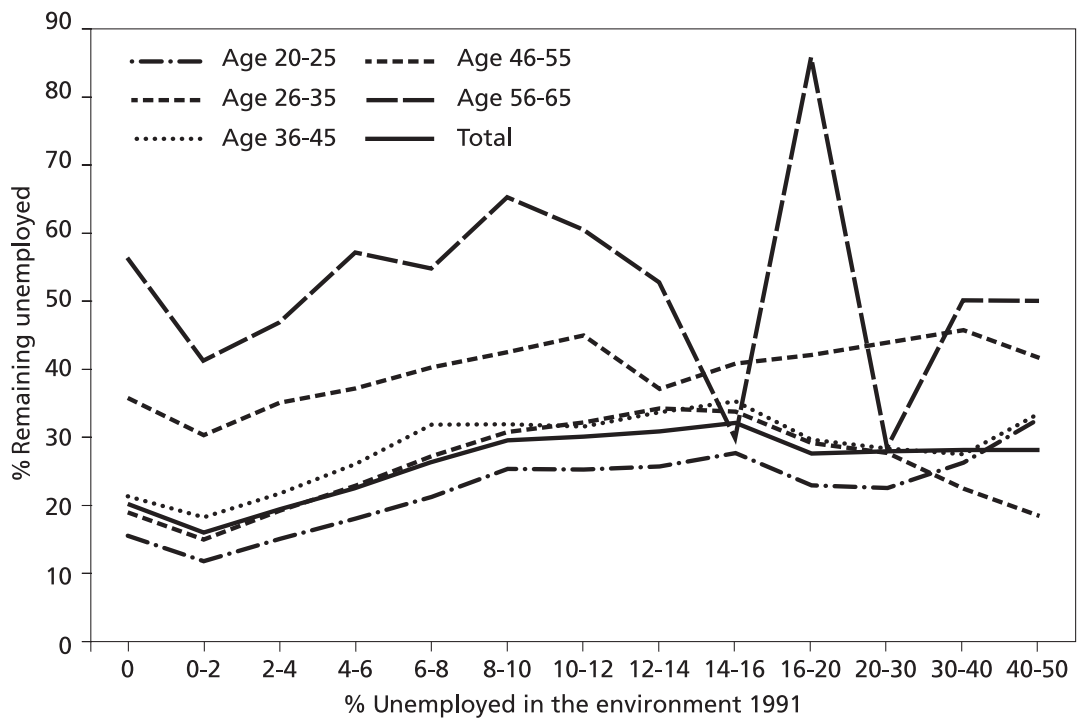

Figure 2 Percentage unemployed remaining unemployed in 1995 and 1999, per environment type, per age category

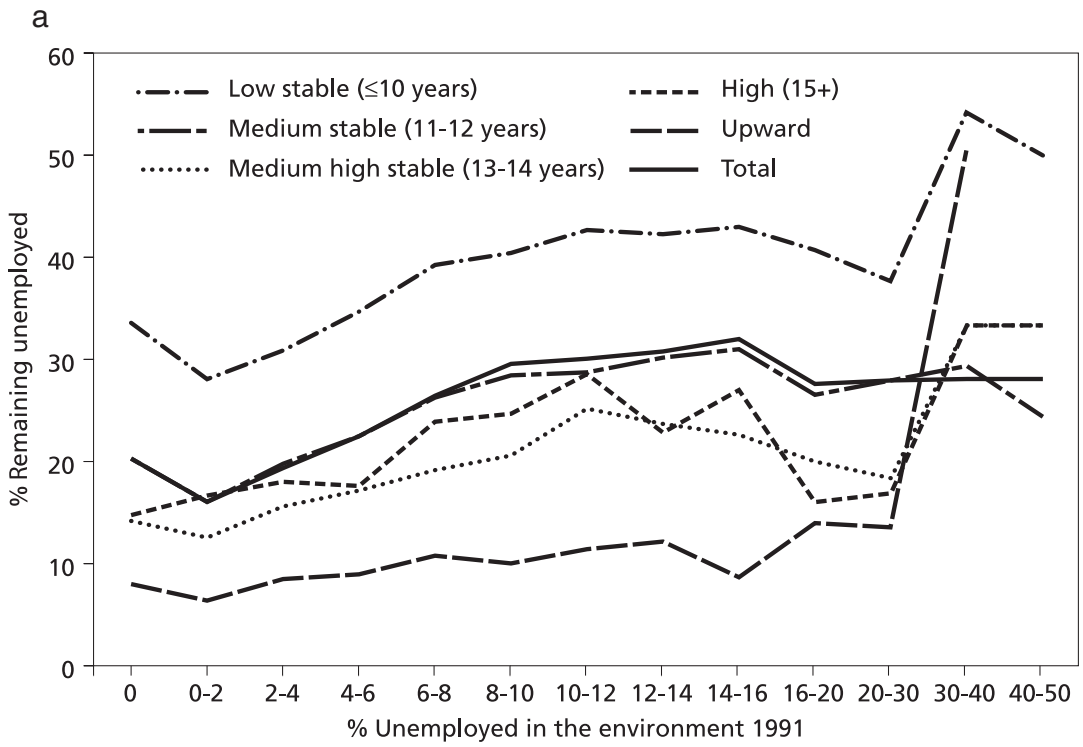

Figure 3a Percentage unemployed remaining unemployed in 1995 and 1999, per environment type, per educational career 1991-5

which it was more difficult to find a job; the period 1995-9 reflects the period of recovery. Figures $3 \mathrm{a}$ and $3 \mathrm{~b}$ reveal some interesting findings. There still appears to be a neighbourhood effect for all individuals who remain in their educational class. That is true for both periods, with the exception of the highly educated. There is a neighbourhood effect for them as well, in 1991-5, when it was very difficult to find a job. However, that neighbourhood effect does seem to be weaker in the period that reflects an upswing of the economy (1995-9). It appears that most of the highly 


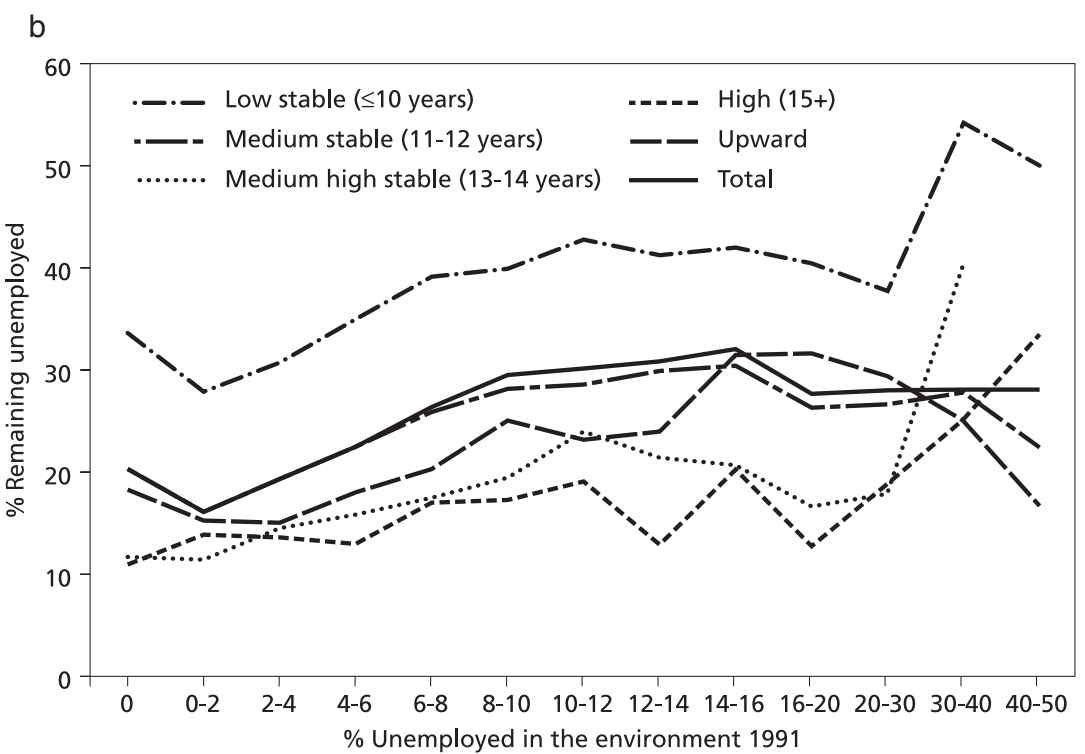

Figure 3b Percentage unemployed remaining unemployed in 1995 and 1999, per environment type, per educational career 1995-9

educated, including those who (still) live in a weaker environment, experience good opportunities when the labour market recovers.

Good opportunities are apparently also available for those who improve their educational position, those who were able to show an upward educational attainment profile. They fare best, and also independently of the environment they are in, when the economy is going rather slow. For the upwardly mobile, in educational terms, no neighbourhood effects could be shown in that period. It may be true that in weaker periods the recruitment process is much tougher than in periods in which the economy is booming. This would help those who show upward educational attainment levels in weaker periods, but not so much in stronger periods. It must also be noted that the Swedish government put enormous resources into adult education in the mid-1990s (as a way of combating unemployment and prepare people for the awaited economic recovery; kunskapslyftet), which resulted in the outflow of substantially larger numbers of upwardly mobile people in the second of our two periods. Upwardly mobile people thus faced much more competition towards the end of the decade.

Two other dimensions require some attention in this debate. The first is the impact of immigrant status; the second is the 'big city' phenomenon. Both dimensions are frequently mentioned as being related to both the creation and existence of so-called 'weak' environments and a lack of employment opportunities. Social problems and concentrations of social problems are first of all associated with the big cities, and from research it is known that unemployment tends to be much higher among immigrants, especially when they arrive from non-Western environments (Andersson, 1998; Integrationsverket, 2003). This is especially true in Sweden, where the labour market participation rate for many non-Western (refugee) immigrant nationalities was less than half compared with that for Swedes for most of the 1990s. Figure 4 reveals that there are independent effects from immigrant status, but also that the neighbourhood effects are still there, for each of the categories distinguished. In Figure 5 we can see that neighbourhood effects also exist for those who do not live in one of the three largest Swedish cities: Stockholm, Malmö or Gothenburg; at the same time it becomes visible that those who do live in one of these cities and those who do move to one of these 


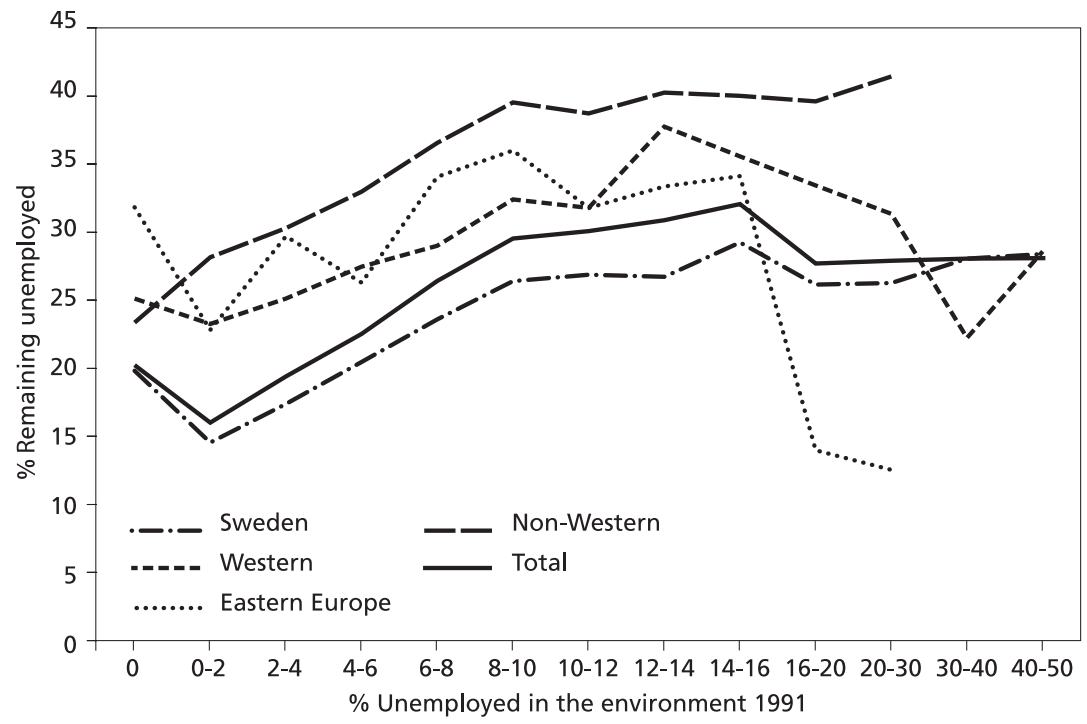

Figure 4 Percentage unemployed remaining unemployed in 1995 and 1999, per environment type, per country of birth

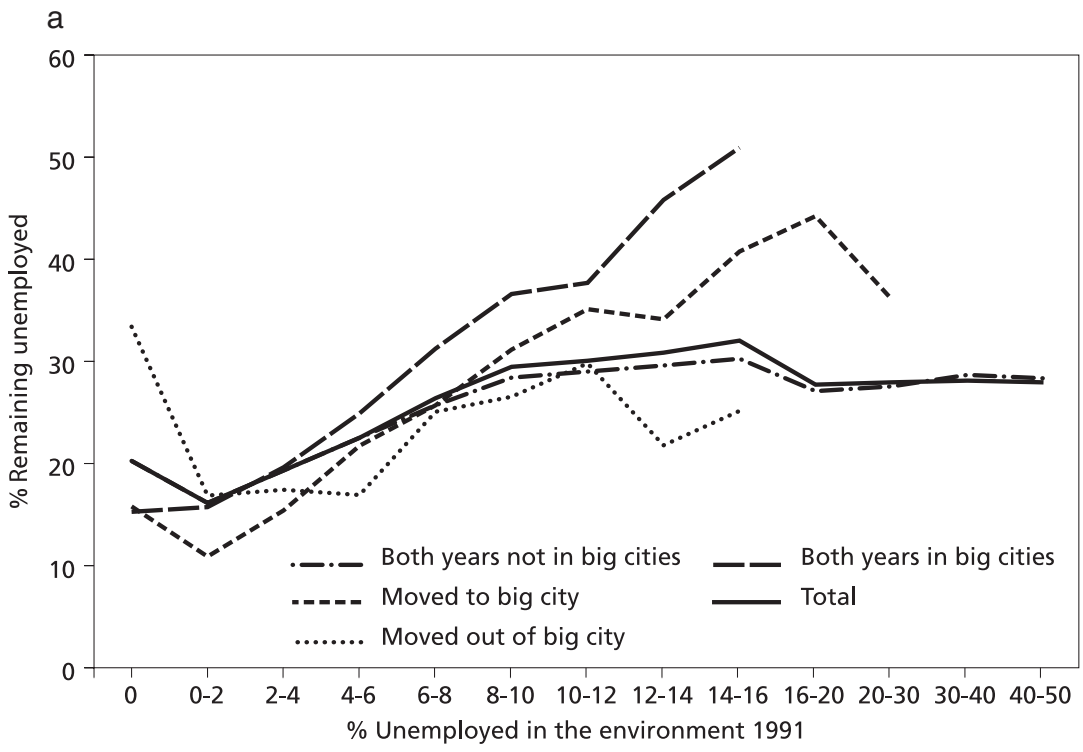

Figure 5a Percentage unemployed remaining unemployed in 1995 and 1999, per environment type, per residential career 1991-5

cities, are more affected by the relative strength or weakness of the environment than those who live elsewhere.

We have included two maps showing the spatial pattern of low employment levels in two different socio-spatial contexts. Figure 6 displays the proportion of people aged 20 64 who were employed in Stockholm neighbourhoods in 1995. Figure 7 shows the same thing for the town of Borlänge, about $250 \mathrm{~km}$ northwest of Stockholm. In the latter case, low employment rates are clearly both an urban and a rural phenomenon (town $=$ smaller 


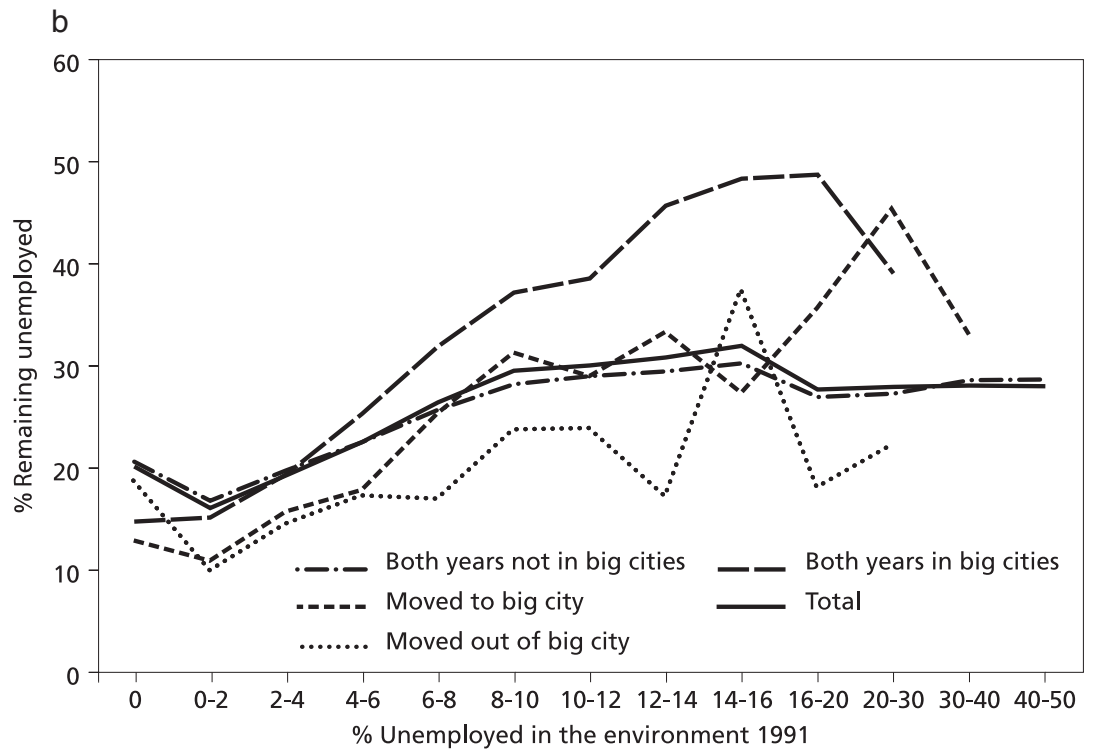

Figure 5b Percentage unemployed remaining unemployed in 1995 and 1999, per environment type, per residential career 1995-9

units). For Stockholm, the map can be seen as an illustration of where poor and immigrant dense neighbourhoods are found - to a large extent they are scattered along the main transportation routs stretching out northwest and southwest from the city centre.

Since it can be imagined that the interaction between change in the level of education, change in the urban orientation - where a lot of educational institutions can be found - and composition of the environment may have a complicated effect on employment opportunities, we also analysed the simultaneous influence of these factors. In Figure 8 relevant graphs are shown. We focused on those who were not living in one of the three big cities in Sweden during the two years we investigated ( $a$ and b) and on those who were living in one of the three big cities ( $c$ and $d$ ). This again shows that the neighbourhood effect is stronger in the big cities than elsewhere; and it also shows that those who improve their educational position are less affected by the neighbourhood composition during economic downturns; however, the neighbourhood effect is still very strong in the big cities when the economy is doing well, even for those who improve their educational position.

We also analysed the relationship with gender and with the dynamics of family status (having children, getting divorced, becoming a single father or single mother, etc.). Gender and all these transformations do impact upon the labour market position of the households involved; but in all cases the neighbourhood effect also remains clear.

\section{Dynamic environments}

Our longitudinal data not only allowed for looking at change in unemployment, but also offered the opportunity to include other dynamic variables. Change in education, in household situation and in the urbanization level of the setting have all been discussed before. However, one important dynamic factor has been left aside so far. That is the change in strength or weakness of the environment itself. Our data allow us to consider whether the environment an individual is living in changes position over time. The unemployment level of an environment may change, or a household may move to 


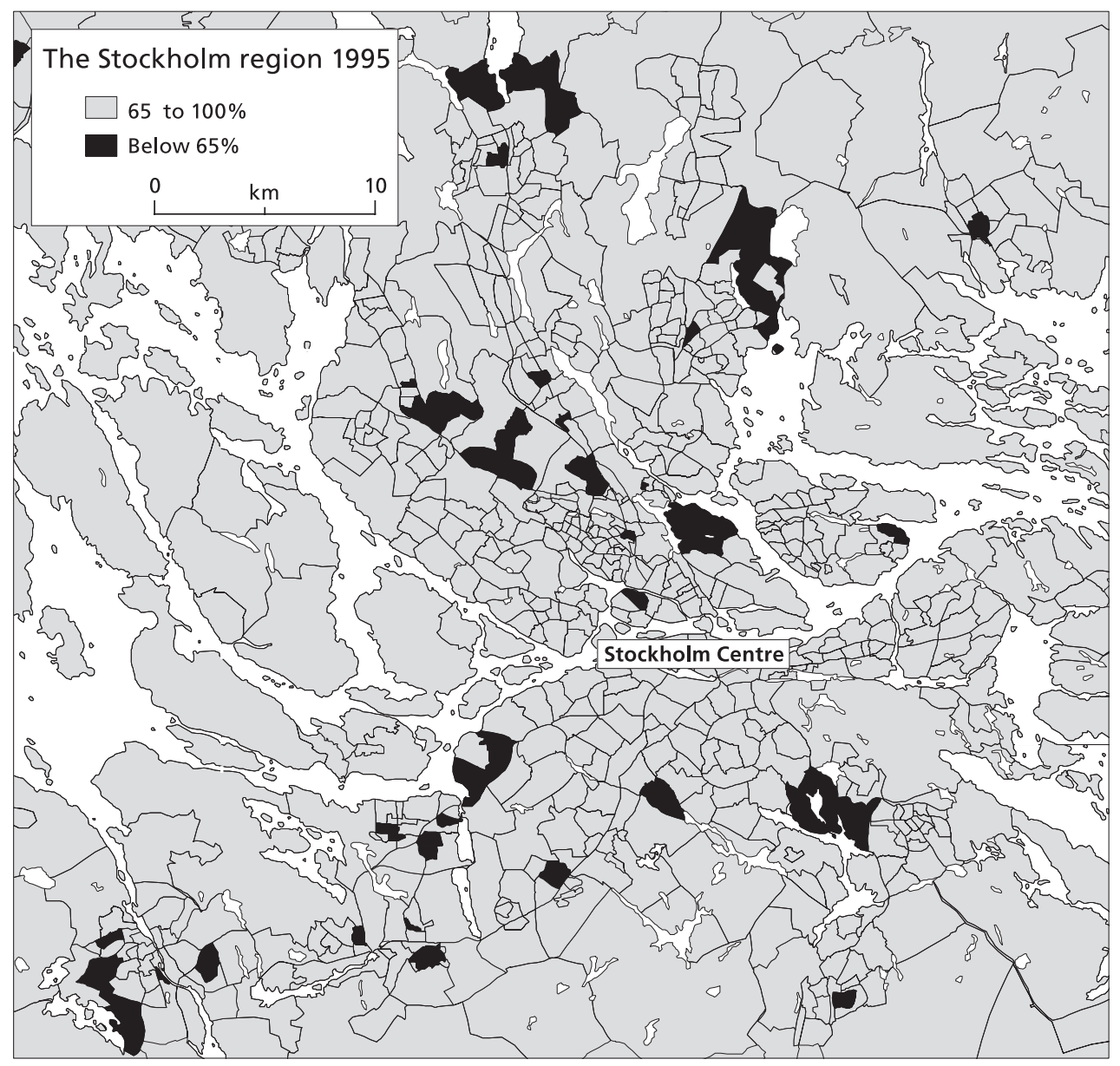

Figure 6 Relative employment frequencies in Stockholm region neighbourhoods in 1995

another environment which is stronger or weaker than the one they came from. We constructed new variables on the basis of the strength of the environment. Classes defined were made comparable through measuring the deviance in terms of standard deviations from the mean. Figure 9 shows the labour market careers of those who were unemployed in 1991 in association with the change of type of neighbourhood involved. Again it shows that there is a clear neighbourhood effect. If we focus on those who had the same environmental conditions in 1991 and 1995 and also control for their educational career in 1991 and 1995, we can see that there still is a neighbourhood effect left. If the difference between downward-moving individuals and upward-moving individuals is considered, a significant difference between these two types can also be revealed. Changing to a stronger environment, be it on site or by residential move, seems to be related to more employment opportunities than changing downward. Similar results could be registered for 1995-9.

\section{Conclusions and evaluation}

In this contribution, we have focused our attention on neighbourhood effects on social opportunities, here operationalized in terms of the impact of the level of unemployment in an individual's environment on the employment opportunities of the individual. While 


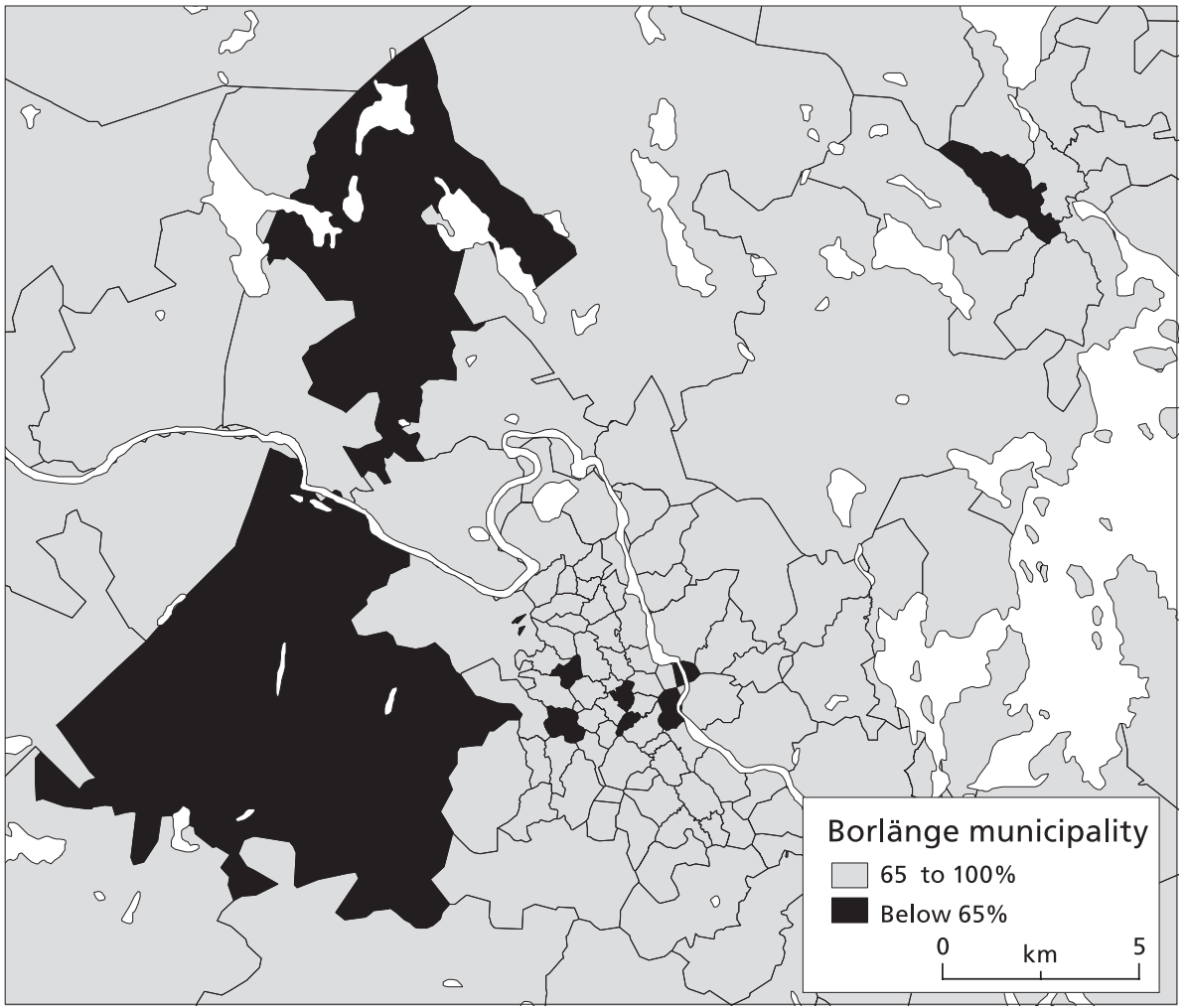

Figure 7 Relative employment frequencies in the municipality of Borlänge in 1995

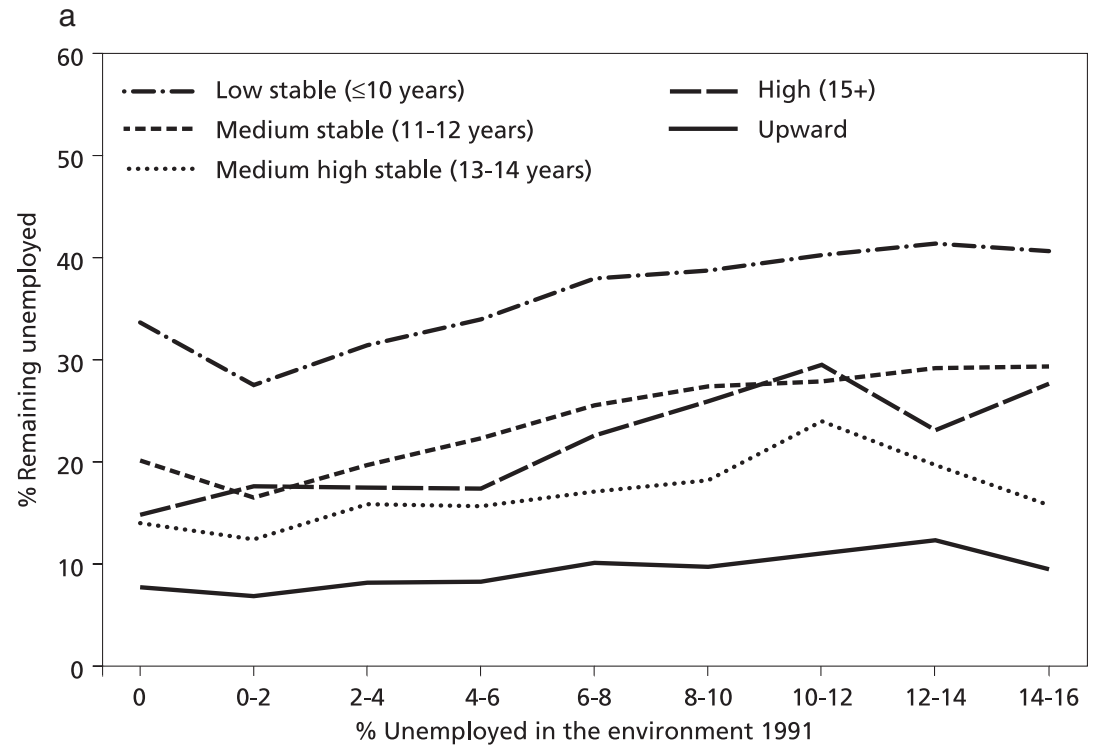

Figure 8a Percentage unemployed remaining unemployed in 1995 and 1999, per environment type, per educational attainment category 1991-5, and not living in one of the three big cities in Sweden in either 1991 or 1995 


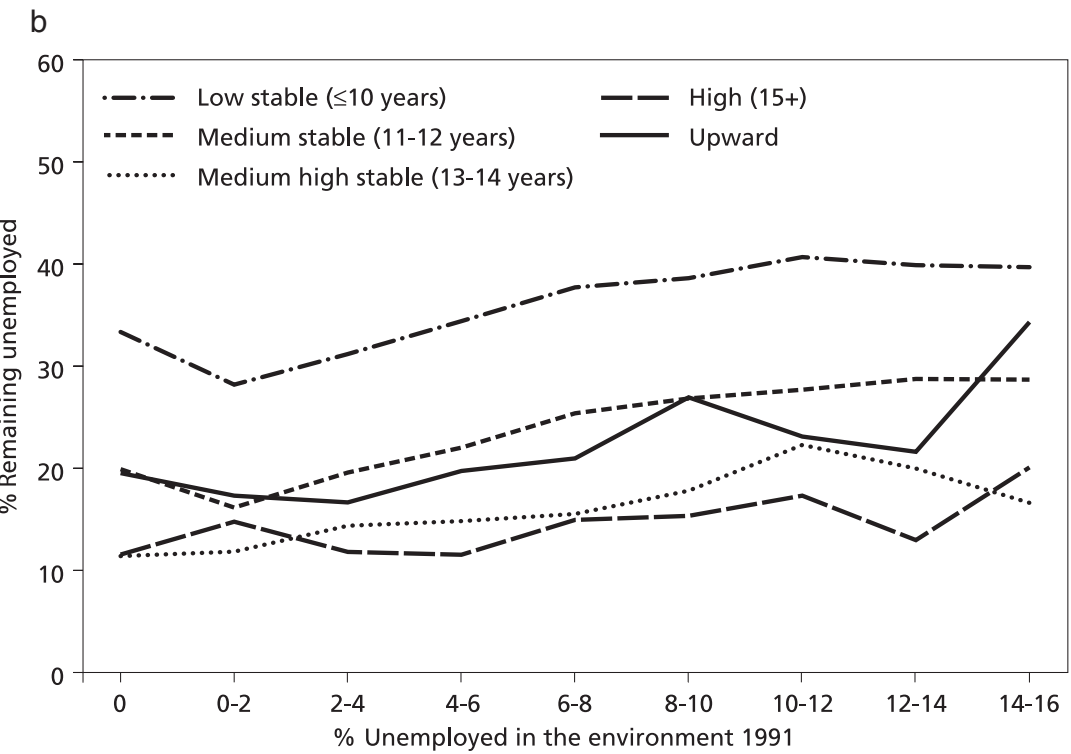

Figure 8b Percentage unemployed remaining unemployed in 1995 and 1999, per environment type, per educational attainment category 1995-9, and not living in one of the three big cities in Sweden in either 1995 or 1999

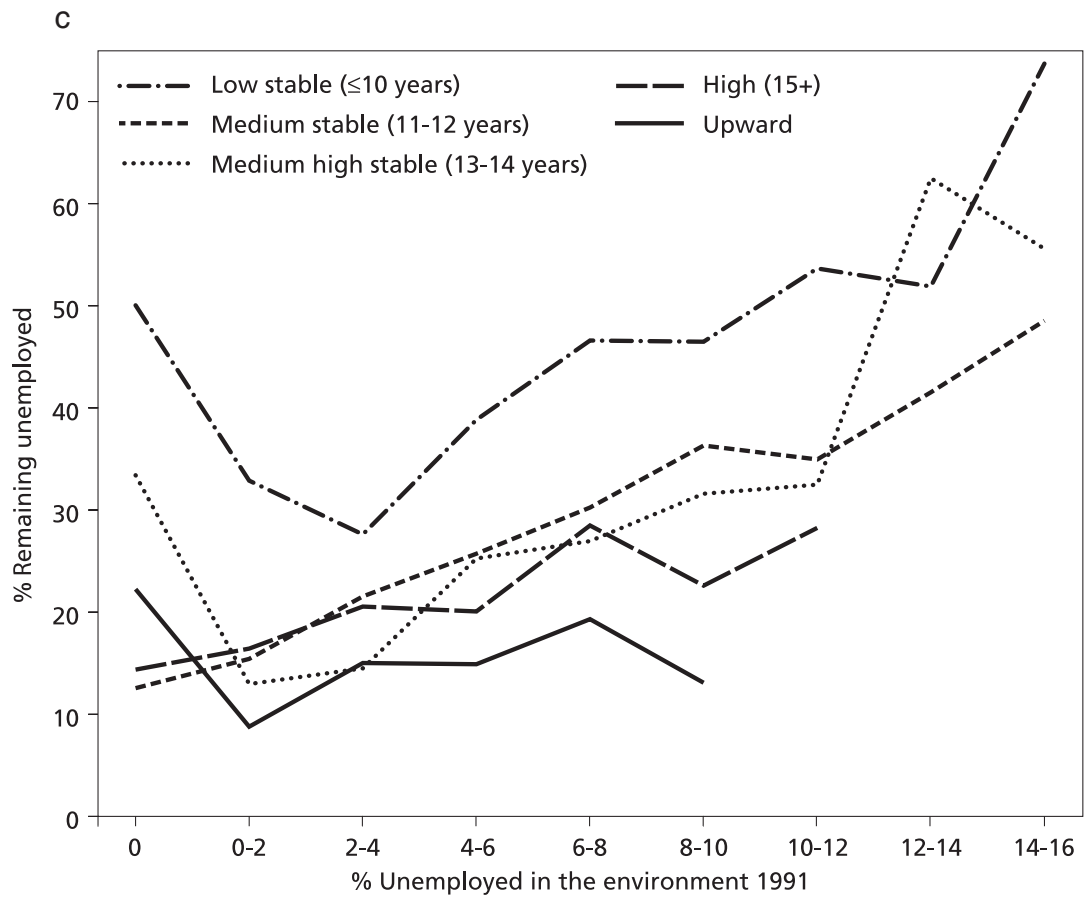

Figure 8c Percentage unemployed remaining unemployed in 1995 and 1999, per environment type, per educational attainment category 1991-5, and living in one of the three big cities in Sweden in both 1991 and 1995 


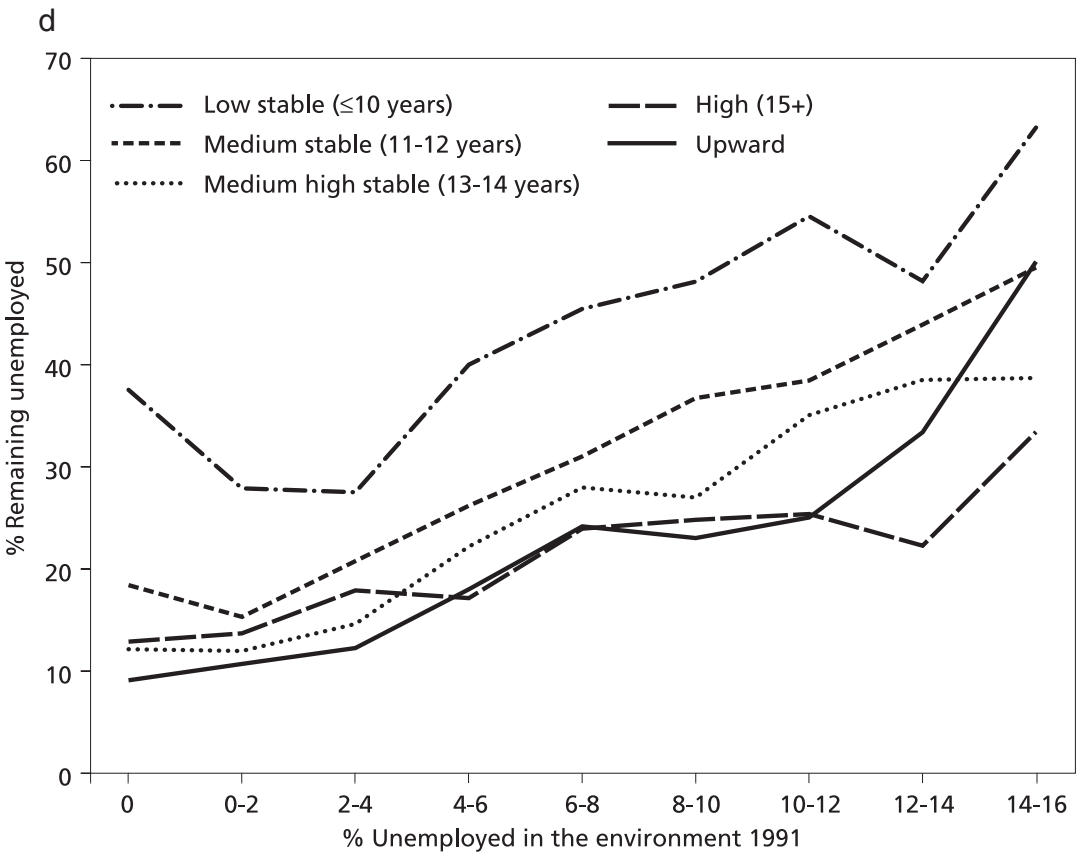

Figure 8d Percentage unemployed remaining unemployed in 1995 and 1999, per environment type, per educational attainment category 1995-9, and living in one of the three big cities in Sweden in both 1995 and 1999

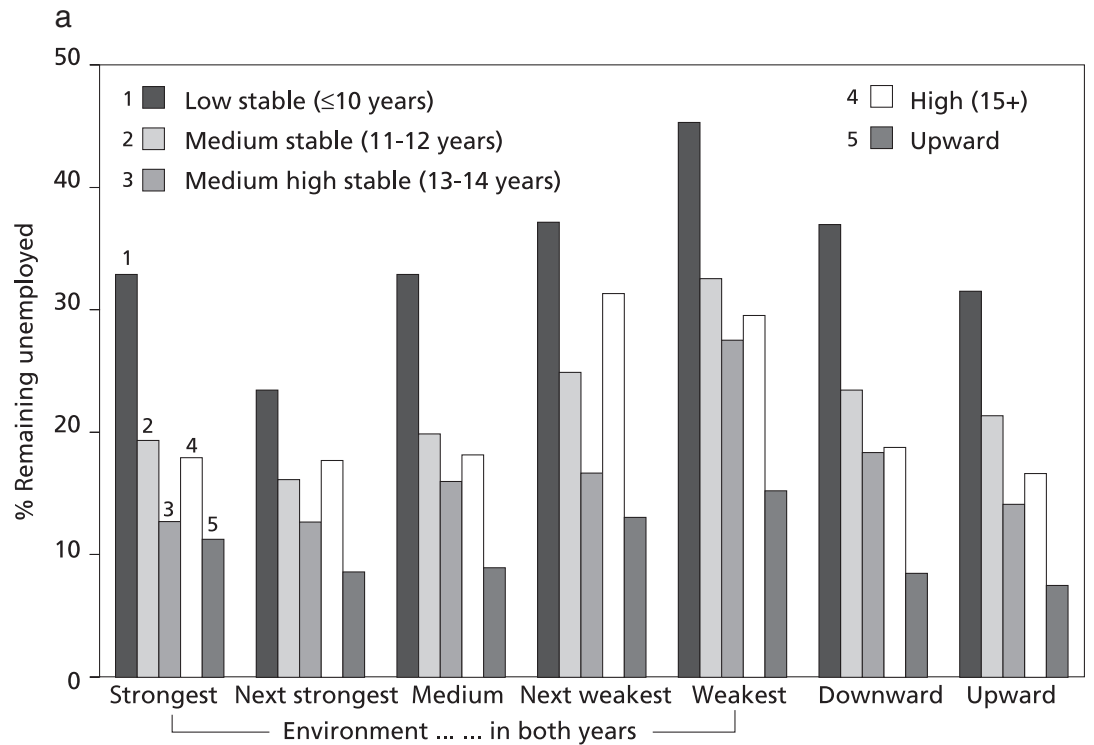

Figure 9a Percentage unemployed remaining unemployed in 1995 and 1999, per dynamic environment type (1991, 1995), per educational attainment category 1991-5 


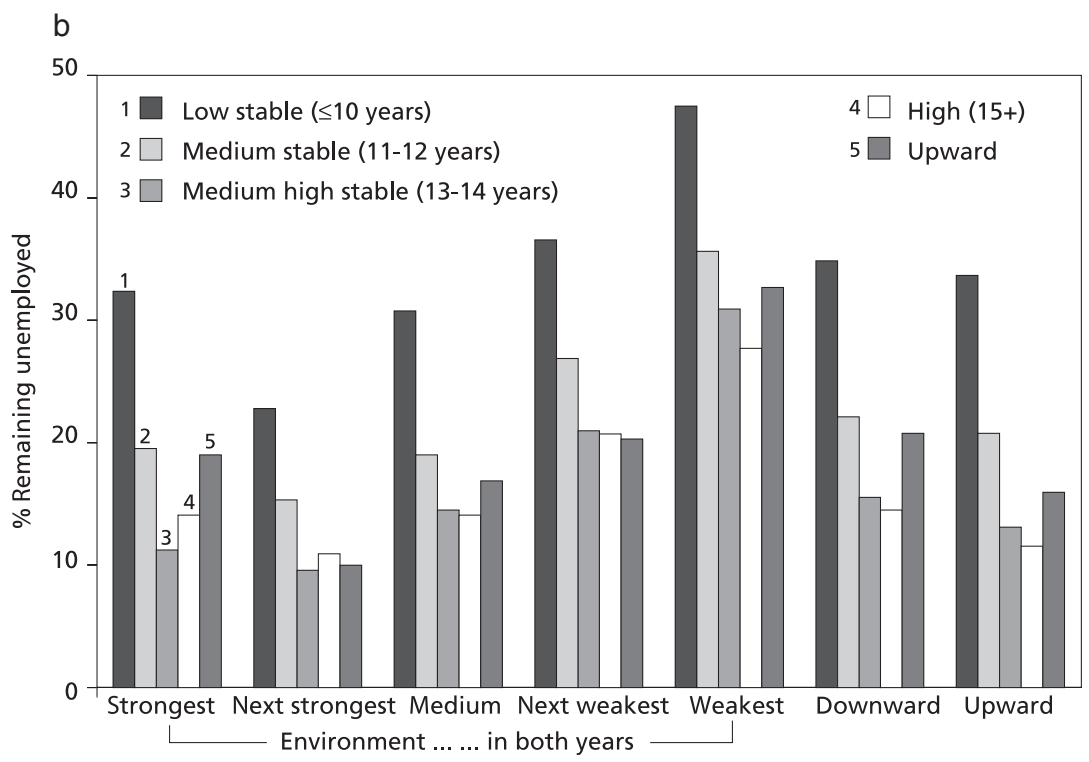

Figure 9b Percentage unemployed remaining unemployed in 1995 and 1999, per dynamic environment type $(1995,1999)$, per educational attainment category 1995-9

analysing that relationship we were able to control for relevant individual and household dimensions and the changes going on in the independent variable sphere.

In comparison to the few European research projects that have used longitudinal data and analysed similar issues, this research project revealed relatively strong associations with the neighbourhood composition. Even after controlling for various relevant dimensions, the neighbourhood effects were clearly visible. The only exceptions we found were connected to individuals who were regarded as having an unstable relation with the labour market and those who showed an improvement in their educational attainment level during economic downturns. The latter could most frequently find a job, even during downturns, and the social environment they lived in did not seem to matter much.

In most of the analyses that were carried out, we found two kinds of so-called thresholds, points at which the linear relations were clearly broken. One is to be found in environments with only one unemployed person - who, we supposed, became stigmatized relatively strongly; the other is where there are around $16 \%$ unemployed in the environment. From that level onward, the probability of staying in unemployment does not increase further. We have argued that this may be related to the capacities of the welfare state, i.e. labour market policies and the competence of specific employment offices. However, further research is needed to explain this rather unexpected outcome.

The peculiar thing to emerge from this analysis is that the outcomes are fairly different from those that were encountered in a research project carried out in the Netherlands (Musterd et al., 2003). That project also focused on employment careers in relation to the social composition of the environment. However, there a much weaker relation between the two variables could be shown. The association even disappeared when controlled for household type or for the urban/non-urban context. That did not happen in Sweden. It must be said that the Swedish dataset is more complete than the Dutch data. In the latter project the educational level could not be directly incorporated, for example. But even then, the direct associations between individual opportunities and neighbourhood compositions were very dissimilar. A simple explanation cannot be provided though. Both Sweden and the Netherlands have to be labelled as strong welfare 
states, in which state intervention in social spheres is rather well developed. Yet, there may be crucial circumstances that differ. Perhaps the Dutch authorities were able to intervene more effectively in the less vulnerable areas than were the Swedish authorities? Another hypothesis is that the more urban and densely populated Dutch society offers fewer obstacles to commuting. Spatial mismatch, i.e. spatial barriers preventing unemployed people from getting in contact with work opportunities, might explain some of the differences. We should also keep in mind that Swedish society has been much more egalitarian than any other society in Europe for a very long period of time. Only relatively recently have inequalities grown up. This may also have led to a relatively strong labelling and stigmatization reaction in the Swedish context. For recent immigrants this may have implied a necessarily greater reliance on their own population category and the relative isolation of areas with high percentages of immigrants from the rest of (urban) society. A complete comparison is, once more, beyond the scope of this article.

But even if we focus simply on the Swedish outcomes, we should be aware of the possibility that other unobserved characteristics of individuals may 'explain' the neighbourhood effects. For example, parental skills in raising children or parental values regarding school attendance (see Ellen and Turner, 1997) may explain quite a few variations, as may any other unobserved factor, such as the mismatch between demand and supply in local labour markets, the costs of bridging certain distances to labour opportunities, and so on.

\section{Policy interventions: more mixed housing?}

While awaiting even more elaborate research one could still ask the question: what does the existence of such a strong neighbourhood effect as was found in Sweden imply for policy makers? Is that a sign that mixed housing policies should be applied? Our response to this debate can only be tentative. As long as we do not have a full understanding of the drivers of neighbourhood effects, it is difficult to say what kinds of policies may be helpful. One thing should be kept in mind on all occasions. That is, even if we can say that neighbourhood effects occur in certain environments, this still does not necessarily imply that these effects are also caused by the housing stock or by the environmental composition. Societies, cities and neighbourhoods are interrelated systems and policy responses to neighbourhood problems, therefore, should take these various levels into account simultaneously. The welfare state at the national level, the labour market and economy at the regional - and global — levels, social networks, socialization and stigmatization processes at the local levels, all probably play a role in understanding what is happening at the very local level. A strong focus on one policy solution, therefore, does not seem to be the proper response, irrespective of the answers to the questions we continue to raise.

Sako Musterd (s.musterd@uva.nl) Department of Geography, Planning and International Development Studies, University of Amsterdam, Nieuwe Prinsengracht 130, 1018 VZ Amsterdam, The Netherlands, and Roger Andersson (Roger.Andersson@ibf.uu.se) Institute for Housing and Urban Research, Uppsala University, Box 785, SE-801 29 Gävle, Sweden.

\section{References}

Andersson, E. (2001) Från Sorgedalen till Glädjehöjden - omgivningens betydelse för socioekonomisk karriär [From valley of sadness to hill of happiness - the significance of surroundings for socioeconomic careers]. Geografiska regionstudier no. 44. $\mathrm{PhD}$ thesis, Department of Social and Economic Geography, Uppsala University, Uppsala.

(2004) From valley of sadness to hill of happiness - the significance of 
surroundings for socio-economic career. Urban Studies, 41.3, 641-59.

Andersson, R. (1998) Socio-spatial dynamics: ethnic divisions of mobility and housing in post-Palme Sweden. Urban Studies 35.3, 397-428.

(2001) Spaces of socialization and social network competition: a study of neighbourhood effects in Stockholm, Sweden. In H.T. Andersen and R. van Kempen (eds.), Governing European cities: social fragmentation and urban governance, Ashgate, Aldershot.

_ and K. Kintrea (2001) Disentangling area effects: evidence from deprived and nondeprived neighbourhoods. Urban Studies 38.12, 2277-98.

Blokland-Potters, T. (2003) Urban bonds. Polity Press, Cambridge.

Buck, N. (2001) Identifying neighbourhood effects. Urban Studies 38.12, 2251-75.

Ellen, I.G. and M.A. Turner (1997) Does neighborhood matter? Assessing recent evidence. Housing Policy Debate 8.4, 83366.

Farwick, A., B. Klagge and W. Taubmannn (2002) Urban poverty in Germany. In I. Schnell and W. Ostendorf (eds.), Studies in segregation and desegregation, Ashgate, Aldershot.

Friedrichs, J. (1998) Do poor neighbourhoods make their residents poorer? Context effects of poverty neighbourhoods on residents. In H.-J. Andress (ed.), Empirical poverty research in comparative perspective, Ashgate, Aldershot.

Galster, G. (2002) Trans-Atlantic perspectives on opportunity, deprivation and the housing nexus. Housing Studies 17.1, 5-12.

_ and S. Killen (1995) The geography of metropolitan opportunity: a reconnaissance and conceptual framework. Housing Policy Debate 6.1, 7-44.

_ and A. Zobel (1998) Will dispersed housing programmes reduce social problems in the US? Housing Studies 13.5, 605-22.

Housing Policy Debate (1995) Special issue 6.1.

Housing Studies (2002) Special issue 17.1.

Housing Studies (2003) Special issue 18.6.

Integrationsverket (2003) Rapport Integration 2002. Board of Integration, Norrköping.

Jacquier, C. (2001) Urban fragmentation and revitalization policies in France: a new urban governance in the making. In H.T. Andersen and R. van Kempen (eds.),
Governing European cities. Social fragmentation, social exclusion and urban governance, Ashgate, Aldershot.

Kain, J.F. (1968) Housing segregation, Negro employment, and metropolitan decentralization. Quarterly Journal of Economics 82.2, 175-97.

(2004) A Pioneer's perspective on the spatial mismatch literature. Urban Studies 41.1, 7-32.

Kearns, A. (2002) Response: from residential disadvantage to opportunity? Reflections on British and European policy and research. Housing Studies 17.1, 145-50.

Leventhal, T. and J. Brooks-Gunn (2000) The neighbourhoods they live in: the effects of neighborhood residence on child and adolescent outcomes. Psychological Bulletin 126.2, 309-37.

Lewis, O. (1966) The culture of poverty. In R.T. LeGates and F. Stout (eds.), the city reader, Routledge, London/New York.

Massey, D.S. and Denton, N.A. (1993) American apartheid. Harvard University Press, Cambridge, MA.

Molina, I. (1997) Stadens rasifiering. Etnisk boendesegregation i folkhemmet

[Racialization of the city. Ethnic residential segregation in the Swedish population]. Geografiska Regionstudier 32, Uppsala Universitet, Kulturgeografiska institutionen.

Musterd, S. (2002) Response: mixed housing policy: a European (Dutch) perspective. Housing Studies 17.1, 139-43.

_ and M. de Winter (1998) Conditions for spatial segregation: some European perspectives. International Journal of Urban and Regional Research 22.4, 665-73. -, H. Priemus and R. van Kempen (1999) Towards undivided cities: the potential of economic revitalisation and housing redifferentiation. Housing Studies 14.5, 573-84.

- W. Ostendorf and S. de Vos (2003) Environmental effects and social mobility. Housing Studies 18.6, 877-92. and R. Andersson (2005) Housing mix, social mix and social opportunities. Urban Affairs Review 40.6, 761-90.

Ostendorf W., S. Musterd and S. de Vos (2001) Social mix and the neighbourhood effect. Policy ambitions and empirical evidence. Housing Studies 16.3, 371-80.

Robson, B., M. Parkinson, M. Boddy and D. Maclennan (2000) The state of English cities. Department of the Environment, Transport and the Regions, London. 
Rosenbaum, J.E., L. Reynolds and S. Deluca (2002) How do places matter? The geography of opportunity, self-efficacy and a look inside the black box of residential mobility. Housing Studies 17.1, 71-82.

Sampson, R.J., J.D. Morenoff and T. GannonRowley (2002) Assessing 'neighbourhood effects': social processes and new directions in research. Annual Review of Sociology 28, 443-78.

Uitermark, J. (2003) 'Social mixing' and the management of disadvantaged neighbourhoods: the Dutch policy of urban restructuring revisited. Urban Studies 40.3, 531-49.

Wacquant, L.J.D. (1993) Urban outcasts: stigma and division in the Black American ghetto and the French urban periphery. International Journal of Urban and Regional Research 17, 366-83.

White, P. (1998) Ideologies, social exclusion and spatial segregation in Paris. In S. Musterd and W. Ostendorf (eds.), Urban segregation and the welfare state: inequality and exclusion in Western cities, Routledge, London.

Whitehead, C. (2002) Response: housing, tenure and opportunity. Housing Studies 17.1, 63-8.

Wilson, W.J. (1987) The truly disadvantaged: the inner city, the underclass, and public policy. University of Chicago Press, Chicago.

\section{Résumé}

La science et la société en général connaissent un vaste débat sur l'existence et l'impact potentiel des 'effets de proximité', la question principale étant: la composition sociale d'un quartier a-t-elle des incidences spécifiques, positives ou négatives, sur les perspectives de carrière de ceux qui y vivent? L'article apporte au débat une étude sur la relation entre la mobilité sociale personnelle et la composition sociale de l'habitat environnant. A cette fin, de nouvelles données suédoises longitudinales, disponibles au niveau individuel, ont été analysées. L'étude s'attache aux carrières professionnelles des individus par rapport aux niveaux d'emploi ou de chomage dans leur environnement personnel. Les effets de l'environnement sur la mobilité sociale ont été isolés en neutralisant les variables disponibles au niveau individuel. On a ensuite pu prendre en compte les changements intervenus dans le temps sur les milieux. Des données individuelles longitudinales ont pu s'appliquer à la période 1991-99. D'après les analyses, l'environnement semble avoir un impact modéré, quoique net, sur les perspectives d'emploi des chômeurs. La pertinence académique de ce travail tient à son apport aux bases théoriques de la relation homme-environnement; la pertinence sociétale est liée aux politiques de quartier et aux politiques de logement visant la mixité sociale qui sont actuellement élaborées dans de multiples points du monde occidental. 